\title{
On The Other Side of the Fence: Practical Tips for First Time Teachers
}

\author{
Dave Murphy \\ Fire Safety Engineering Technology \\ The University of North Carolina at Charlotte
}

\section{To teach is to learn twice over - Joseph Joubert}

The bell rings, the door shuts, and suddenly you are faced with a multitude of inquisitive faces looking expectantly at you. The room slowly becomes quiet ... what next? Your new vantage point provides an unfamiliar view of the awesome responsibilities required of your new position. You have invested hours in the preparation of your class. Your lesson plan is complete to the smallest detail.

- Will your delivery be effective? At a minimum, your initial meeting should exhibit self-confidence a good working knowledge of the subject.

- Will students listen? Ground rules for the class should be explained up front. An explanation of your expectations could prove helpful.

- Will they participate? Emphasize the importance of class interaction. Explain that differing opinions are encouraged.

- Are you assured that your efforts will culminate in an interesting and informative class? You should express your sincere desire in providing a creative learning environment.

Most teachers take their responsibilities very seriously. As a rule, new faculty set tougher personal standards for themselves and constantly seeks innovations that will establish them as credible instructors and satisfy the needs of the students. In reality, how do we know if student needs are actually being met? How do we measure our successes and shortcomings? As a new faculty member, I try to use my years of student experience as my guide to class preparation. I subscribe to the old adage "do unto others... as you would have them do unto you". In my goal of becoming a better teacher, I utilize and recommend the following common-sense strategies:

Utilize an up-to-date text. Finding and adopting a well-written, current text is the first step of the class structuring process. The textbook search should ideally begin well in advance of the upcoming semester. This will allow ample time to review and begin the class outline process. Seek out publishers that supply textbooks specific to your subject. Your colleagues will be able to provide the names of publisher representatives that routinely provide free desk copies in the hope that they will be chosen as the choice for your class. Most textbooks are written in a manner that builds upon the preceding chapters. Whenever possible and for the sake of simplicity, lessons should follow the chapter outline as presented in the text. Avoid textbooks 
that present material in a manner of which you are not comfortable or you do not necessarily agree. Class preparation and student comprehension is much easier with a well written text.

Develop an appropriate syllabus and stick to it. As a student, how many times was the syllabus given to you at the beginning of the semester and not adhered to? This is extremely frustrating and disrespectful to the student. The syllabus should serve as the definitive class outline. If properly designed and administered, the syllabus will serve as a guide to all students, and can be especially helpful to those who may miss class due to illness or other unforeseen circumstances. In addition, the same benefits are equally useful to you as the instructor. With much forethought, your class will be guided by a dynamic action plan that will hopefully lessen the stresses of the on-going semester.

Encourage student interaction. Pedagogical and androgogical theories have long alluded to the fact that students like to be heard. Have students formally introduce each other with a brief bio. As an icebreaker, I usually provide a format to follow and devote most of the first class meeting to student introductions. You should structure the biographical format to extract information regarding specific elements such as hobbies, mentors, and other less formal information. After the short bios are completed on a provided index card, each student will introduce his or her classmate. This exchange will help establish a comfort level in the class. The cards also provide an immediate class database for the instructor. Once known, the diverse backgrounds and experiences of the students will enhance the class. It is imperative that students learn to interact and appreciate differing viewpoints.

Challenge the text in class discussions. All writers are, in effect, expressing an opinion. This opinion should always be subject to scrutiny - there may be a better way! When a student questions the validity of a statement supported by the text, it provides an excellent opportunity to perpetuate classroom discussion. A wise teacher will always be honest with their students and not be afraid to say "I do not know". Many teachers seem to steer away form issues that they no nothing about. A more effective strategy would possibly be to anticipate uncomfortable points of discussion. A truly prepared teacher should not wait until they are confronted with such an issue and possibly unable to elaborate.

Get to know your students - your customers. Customer service is a hot topic among quality advocates these days. As educators, it is easy to lose sight of that concept. I've known many faculty members who treated students as second-class citizens. They never really knew the students and did not wish to know them. As faculty, we should never forget that the students are the reasons for our paycheck. Institutions of higher learning are not necessarily a monopoly, students do have the ability to leave and go elsewhere if they so desire. As educators, we must not lose sight of our primary mission. I prefer to be known as not only a teacher, but as an enabler. I count the encouragement and friendship of my former professors as a major factor in every life success to date. A caring instructor can unknowingly motivate students to excel. Your attention to customer service will ultimately pay huge dividends to the student, you and the university.

Accompany the lecture with some type of visual media. Beware of the monotone talking head with chalk in hand. While the old "chalk and talk" method is still acceptable, you should 
not be frozen in this method of delivery. Today's students are of the video age, and as a result, they are more responsive to visual media. Presentations infused with multimedia are very conducive the learning process. Interesting instructors will be innovative and experiment with multiple delivery methods.

Align the text-based lesson with applicable life situations at every opportunity. Knowledge without application is fruitless. If you want to pique student interest, infuse the lesson plan with true-to-life situations they will encounter in the workplace. Non-traditional students are a major asset in this area. Their experience and unique insight can often spur the discussion with relevant and interesting facts.

Develop a contemporary outline that incorporates the diversity of the class. Diversity is another buzzword that we hear a lot these days. The fact is, most cultures do hold differing views of normal everyday practices. Again, we must engage the students to determine this. In order to be effective, the class must incorporate modern problems and present innovative solutions. Assignments should require that students investigate the many resources provided by the library. Students will heighten research skills while discerning the latest information.

Learning is a magical event, and often occurs in unexpected ways. Problems that are diverse and contemporary nature will usually create an environment that is conducive to learning.

Utilize group discussions as much as possible. It is nearly impossible for one individual to hold the attention of the class one hundred percent of the time. A successful strategy might include using groups to dissect \& present critical questions relevant to the class. This effort will stimulate class interaction and hone the presentation skills of the group. The subject will be much more interesting if you engage all members of the class.

Encourage critical thinking. Critical thinking is a crucial requirement in every discipline. Pose questions in a manner that requires thinking - not memorization. Organize group activities that make students defend an unpopular opinion. Develop written assignments and examinations that perpetuate individual thought. Creative essay or short answer questions should be included whenever possible in every exam.

Require public speaking in your classes. Public speaking abilities are essential to the success of every professional. Student presentations that require speaking should accompany each class module. It is no mistake that every college accreditation process encourages public speaking as an important step in meeting desired goals. You might consider peer grading to provide the presenter with immediate feedback. The presentations will enhance your class and develop critical presentation skills for the students.

Seek student feedback. How are you doing as an instructor? If you truly want to know, ask. Self-assessment is the first step of self-improvement. Mid-term evaluations are frequently used at many universities, while others do not to do so. In addition to periodically asking "How am I doing?", a good instructor may choose to construct their own midterm evaluation. Care should be given to structure the evaluation so that it promotes constructive comments. Explain the results in class and implement positive changes as practical. The changes will not only improve the class, it demonstrates your respect for the students and their opinions. 
Publicly acknowledge well-written papers and presentations. Almost everyone appreciates a kind word or pat on the back. Students are no exception. With the student's permission, present examples of exemplary work to the class. Perhaps the student presented the latest research, or simply followed the paper format as listed in the syllabus. This display will reinforce positive aspects and may clarify what is not acceptable. Publicly praise excellent student contributions in class. The end result can be contagious.

Be flexible and seek constant improvement. In the modern world, technological innovations make personal change inevitable. We simply cannot exist as we are. In academia, as in other professions, we must strive to stay abreast of innovations that better enable us to do our job better. For the latest information, most universities offer some type of frequent newsletter. In our quest for constant improvement, we must read the latest literature, attend relevant seminars, and investigate other learning opportunities. In short, we must be open to change and be in tune with today's world.

Many elements must indeed combine to make a successful teacher. Volumes have been written on numerous pedagogical and androgogical research theories. It does not matter what we know, if we are not able to convey it. Newly appointed faculty members should be daring as they begin their new career. Your students will not only notice and appreciate your enthusiasm, they will respond to it.

Joubert, Joseph. as quoted from $21^{\text {st }}$ Century Dictionary Of Quotations . Dell Publishing. 1993.

\section{DAVE MURPHY}

Dave Murphy retired from the Richmond (Kentucky) Fire Department as Assistant Chief. Upon retirement, he entered the industrial sector as a safety director for AFG Industries. He is currently an Assistant Professor in the Fire Safety Engineering Technology program located at The University of North Carolina at Charlotte. 